\title{
Knowledge Management Issues For Maintenance of Automated Production Systems
}

\author{
Jacek Reiner ${ }^{1}$, Jan Koch ${ }^{1}$, Irene Krebs ${ }^{2}$, Stefan Schnabel ${ }^{1}$ and Thomas Siech ${ }^{1}$ \\ 1) Wroclaw University of Technology, Centre for Advanced Manufacturing Technologies, \\ Lukasiewicza 3/5, PL-50-371 Wroclaw, Poland. \\ Email: \{j.reiner, j.koch, s.schnabel, t.siech\}@camt.pl \\ 2) Brandenburg Technical University of Cottbus, Faculty of Mechanical, Electrical and \\ Industrial Engineering Chair of Information Systems, Universitatsplatz 3-4 D, D-03044 \\ Cottbus, Germany. \\ Email:krebs@iit.tu-cottbus.de
}

\begin{abstract}
Today's maintenance approach is functional oriented and mostly it is understood as hardware preventative actions. The changing share of mechanics, electronics and software cost of automated production systems call for new competences and responsibility for efficient maintenance. The paper presents automated production system which is considered as socio-technical system whose effective maintenance is based on knowledge management. In this paper Object-Oriented Modelling and UML were pointed to, as enhancing communication and documentation effectiveness in interdisciplinary teams responsible for maintenance.
\end{abstract}

Keywords: Maintenance, Automation, Knowledge management, Human-machine, Objectoriented, UML

\section{INTRODUCTION}

Looking for high product quality, production flexibility and cost cutting, the automation level of production systems is growing. The PCs, Internet services and even multimedia (vision systems) are migrating from the office world into industrial environment. Thanks to the increasing role of software in automated production systems, which is comparable with mechanics in 
$40 \%$ share (PRITSHOW et al. 2000), the system functionality is developing, while their usage should become more and more user-friendly.

Do such superlatives characterise the maintenance of the above systems? It is visible, that the advance, scale, complication and complexity of the above systems is growing rapidly. Particularly, the complexity is inseparably linked with human-being, and its reduction is not achievable by decomposition, but only by systematic approach. The systematic approach is essential for new development, but as well as for service, modernisation and upgrade. The two second activities are essential for dynamic changes of products and production technologies within the life cycle of automated production system.

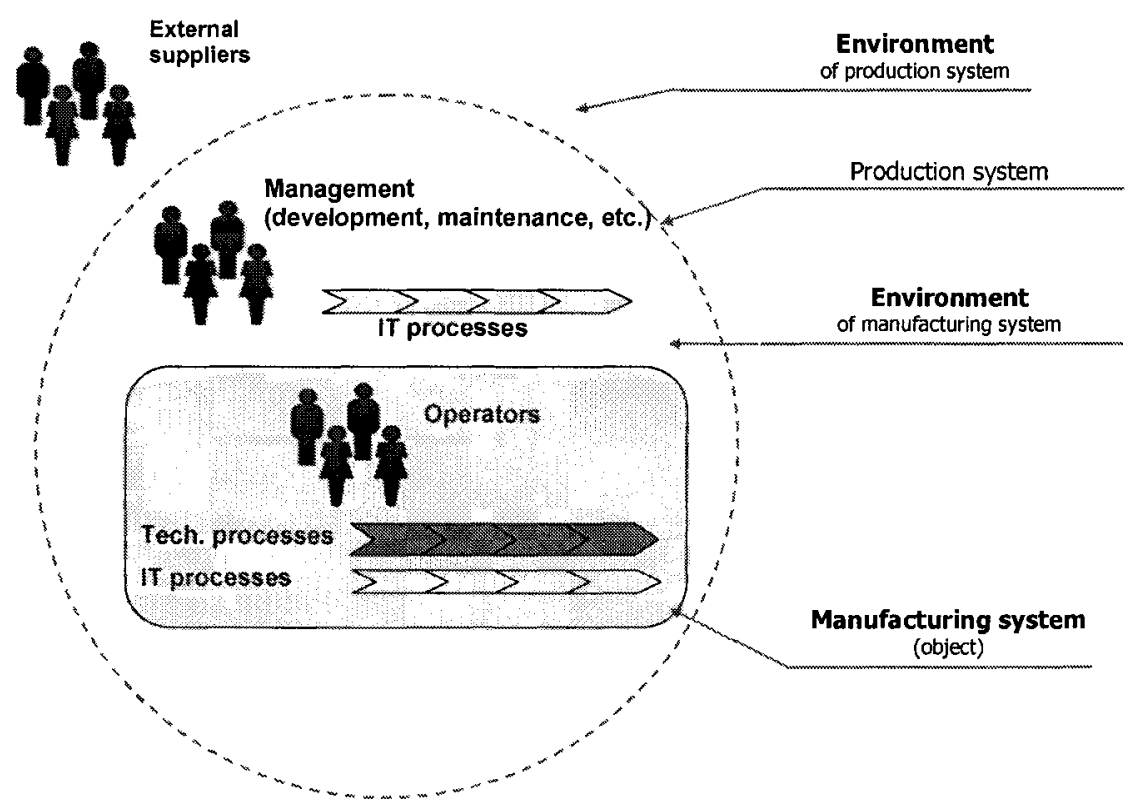

Figure 1. Socio-technical system

Therefore, a holistic approach to automated manufacturing systems, which integrates people, technological and IT processes into socio-technical systems for maintenance, is essential (Figure 1). The attention should be focused even more on strategy level of the "human-technology", reaching its philosophical roots ("is the robot the extension of human's arm, or is the human the extension of robot's arm?") (EVERSHEIM et al. 2002). Such holistic approach will appreciate maintenance process - the life cycle of automated production systems. 


\section{MAINTENANCE OF SOCIO-TECHNICAL SYSTEMS}

"Assets maintenance" is the most capacious term regarding maintenance, which includes: buildings facilities, transportation means, production systems, etc. The maintenance of automated production systems through sociotechnical perspective distinguishes three main domains: hardware, software, and human-being.

1. Hardware maintenance is a well developed division which supports production equipment. The service role (breakdowns reparation), is minimised by preventive approach. The domain has developed variety of maturity integrated methods, techniques and tools e.g. TPM (Total Productive Maintenance). A lot of services is outsourced. The relations between equipment users (production) and its carers (maintainers) is differently organised. Mainly the supervision, e.g. for new developments and modifications on the plant, is restricted to the planning division.

2. Software maintenance consists of four types of actions: corrective, adaptive, perfective, preventative. Activity share shows that more than $75 \%$ of them concerns new functionality and safety upgrade or development. Because the software is not so open and more extensive, maintenance requires deep knowledge about internal SW structure and behaviour, as well as development environment. Therefore, the user commitment for maintenance is limited. On the other side, the software can offer very extensive configuration. The role responsible for SW maintenance is an "administrator", whose responsibility grows for Internet connected systems.

3. "Human maintenance" - as an expression is not used. Staff development is managed by Human Resources (HR) or Human Capital Management divisions. Through technical and social competences profiles, the people's carrier development paths are planned. The motivation and engagement are stimulated with difficulty (GRAF, HENCKEL 2003) while effective team working pays important role.

The above analysis indicates that each area has developed not only its own tools and methodology but also language and even its sub-culture. Despite of process oriented approach for analysis of value chains, the maintenance is not treated as integration of the above components. The maintenance of socio-technical system is complex, therefore, the problem decomposition hides the inter-domain problems.

1. Classical maintenance and planning divisions require different competences than software maintenance. The hardware and software life cycles depend on each other, and therefore, today's planning division should be 
integrated more efficiently with software maintenance and development teams. The integration will be especially difficult if the software maintenance is supported by external companies (outsourcing).

2. Automation leads to replacement of humans manual or cognitive abilities. Interfaces are becoming more user-friendly, but it paradoxically appears that growing "machines intelligence" requires more knowledge from the user. It does not concern a typical operation but emergency, errors, warnings, configuration or manual modes. The variety of configuration possibilities makes the system more flexible, but simultaneously weakens the system safety and reliability. Therefore, the user needs more training and "playing" with machine configuration for refreshment of system functionality, which is not frequently used.

3. The high specialisation, distinct jargon between domain experts requires better communication between them. The understanding can be only expanded top-down, which means from the strategic and logical issues which should truly integrate all of the team members.
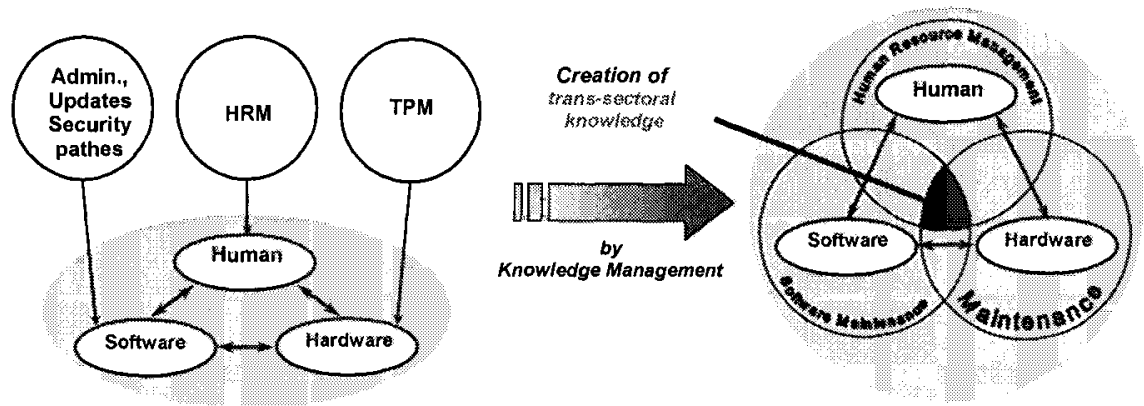

Figure 2. Maintenance of Socio-Technical System

(Source: KOCH et al. 2003, p. 178; modified)

Researching for strategic approach referring to the above identified problems directs to better information management, team working and knowledge transfer.

\section{KNOWLEDGE MANAGEMENT}

Presently, knowledge management (KM) provokes lively discussions in the scientific and industrial world. Some believe that KM is the panacea for today's company's difficulties, the others sceptically call it just "fashion" or even "new religion". 
The discussion entry point should be unequivocal defining of the term "knowledge" - which seams to be impossible. If we accept that knowledge is only in human heads, then we have to radically distance from information technologies, which can only support information storage and communication. In this case the human is irreplaceable for knowledge creating and usage. Knowledge communication and processing cannot be efficiently realised based on information technology.

Is knowledge measurable in that case? There are several approaches how to measure human knowledge using competences tests. Analogous to intelligence testing (IQ, emotional intelligence) the question of reliability and how to keep the captures updated is still open.

There are two main approaches to knowledge processes supporting. The first one is "knowledge management" which tends towards control by mapping, measurement, evaluation with IT support. The second approach is called "knowledge creation" in order to stress that the rational management pays insignificant role. The creation is based on "soft factors" like emotions, understanding and community. The above approaches focus human role differently (object or subject), which derive from two philosophical roots of Western or Japanese culture (TAKEUCHI 1998). Therefore, the knowledge support implementation has to respect environmental culture.

There are several different approaches for knowledge management, which start with problem domain analysis - see Table 1.

Table 1. Different approaches for KM implementation

\begin{tabular}{lll}
\hline Dimensions & Approach & Author \\
\hline \multirow{2}{*}{ Type of knowledge } & episteme, techne, phronesis & Arystoteles \\
& know-what, know-why, know-how, know-who & $\begin{array}{l}\text { Lundval, } \\
\text { Johnson }\end{array}$ \\
Type of knowledge & implicit, explicit & $\begin{array}{l}\text { Nonaka, } \\
\text { Takeuchi }\end{array}$ \\
System components & human, technology, organisation & Bullinger, et al. \\
Supply chain & internal - external & $\begin{array}{l}\text { Ruemler, } \\
\text { Reinhard }\end{array}$ \\
Core activities & $\begin{array}{l}\text { identification, creation, storage, allocation, use, } \\
\text { oblivion, evaluation }\end{array}$ & Probst, et al \\
\hline
\end{tabular}

The implementable solutions supporting knowledge management are called KM tools. They are represented by variety of classes: information exchange, information mining, creativity, etc. 


\section{KNOWLEDGE MANAGEMENT TOOL FOR MAINTENANCE}

The analysis of the complex automated production systems indicates that maintenance effectiveness will depend more and more on knowledge of the system. The new automated production systems include hardware, software, documentation, training and support. The inconsistency between each of them can occur if understanding or resources are not sufficient.

Multidisciplinary competences and distributed responsibility among the users of automated production systems pay attention to need and support for knowledge sharing and archiving.
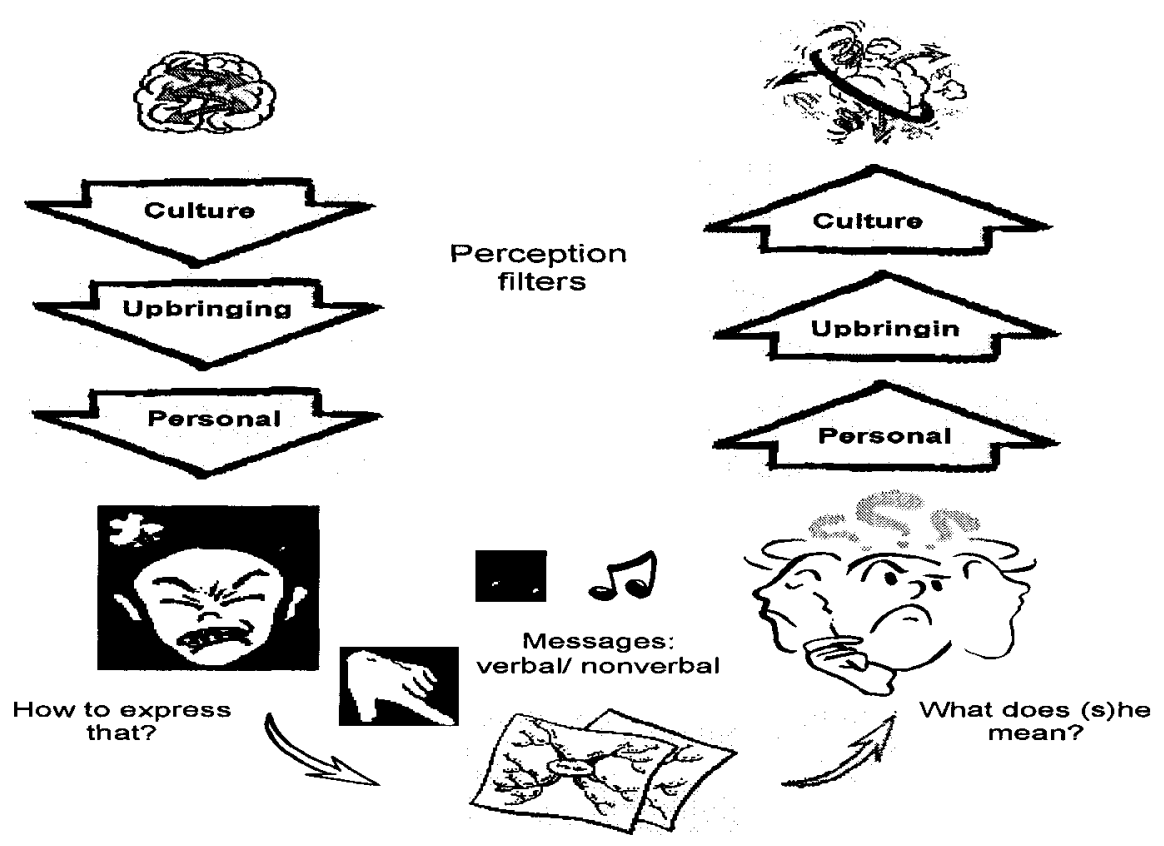

Figure 3. Interpersonal communication [JR]

At CAMT (REINER 2003), "Object-Oriented Modelling and UML for Manufacturing Automation" was proposed, as a knowledge management tool. The tool can be also implemented to support automation maintenance processes.

The knowledge management tool is based on interpersonal communication analysis. The communication chain (Figure 3 ) identifies perception filters formed by culture, upbringing and personal abilities. The filters determine paradigm - the way of thinking and building mental models. Diagrammatic which deals with graphical communication languages, offers 
tools for projection of the mental models. Languages with defined syntax and semantic are means for human communication and produce tangible expressions. The proposed knowledge tool uses object-oriented paradigm and Unified Modelling Language (UML). The solution is formulated as layered competences model. Above the lowest layer of Manufacturing Automation, the Modelling, Objectory and UML are defined (Figure 4). The model forms a platform for four modelling competences: business automation processes, logical process structure, use cases and systems dynamics. The efficient use of proposed methodology requires appropriate implementation. The implementation process consists of four stages: training, demonstrator building, expansion and usage. The demonstrator delivers evaluation for introduced knowledge management projects.

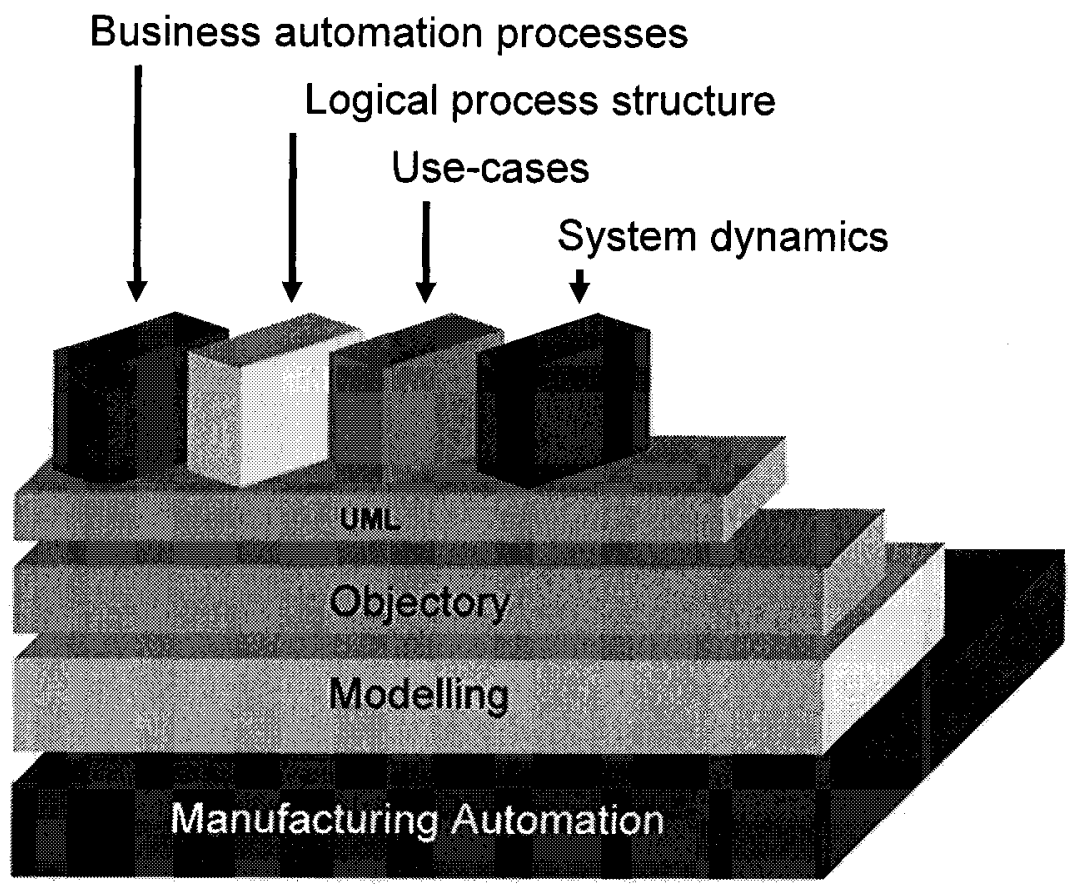

Figure 4. Communication tool OOMMA [JR]

The proposed methodology was implemented in an interdisciplinary team responsible for operation, maintenance and development of automated production system. The evaluation showed that objectory and UML can be easily learned and used by non programmers for modelling real world and communication. The methodology was used as a communication platform 
for better knowledge exchange between experts and to support knowledge consistency.

\section{CONCLUSION}

In the above article the reader's attention was turned to the influence of the introduction of the PC's, the Internet services and multimedia from the office world, on the understanding of maintenance of automated production systems. The need and profits resulting from integrated process analysis of socio-technical system (human, technology, information) was illustrated.

Critical discussion of the knowledge management issues proves that despite incoherence and misunderstandings, its elements may and should support maintenance processes in a company. For their success it is important to consider human-being and organisational culture in the foreground, and information technology in the background.

In this article Object-Oriented Modelling and UML were pointed to, as enhancing communication and documentation knowledge management tool, which can improve effectiveness in interdisciplinary teams responsible for maintenance of advanced automated production systems.

\section{ACKNOWLEDGEMENT}

The above research has been performed in an international and interdisciplinary team (CAMT-PWr and BTU-Cottbus) thanks to financial support of the European Commission within the project Centre of Excellence (ICA12000-70011).

\section{REFERENCES}

BULLINGER, H. J.; WÖRNER, K.; PRIETO, J.:

Wissensmanagement - Modelle und Strategien für die Praxis.

In: Wissensmanagement - Schritte zum intelligenten Unternehmen.

Ed.: Bürgel, H. D.

Berlin, Springer 1998. 
EVERSHEIM, W. et al.:

Mit e-Engineering zum i3- Engineering.

In: Wettbewerbsfaktor Produktionstechnik: Aachener Perspektiven.

Edts.: KLOCKE, Fritz; EVERSHEIM, Walter; SCHUH, Günther; PFEIFER, Tilo;

WECK, Manfred.

Aachen: Shaker Verlag, 2002.

GRAF HENCKEL VON DONNERSMARCK, H.:

Überwindung von Grenzen als Herausforderung der Erfahrung eigener Begrenztheit. Münchener Kolloquium 2003

KOCH, Jan; KREBS, Irene; REINER, Jacek; SCHNABEL, Stefan; SIECH, Thomas:

Knowledge Management Issues for Maintenance of Automated Production Systems.

In: Current Trends in Production Management.

Eds.: ZÜLCH, Gert; STOWASSER, Sascha; JAGDEV, Harinder S.

Aachen: Shaker Verlag, 2003, pp. 174-180.

(esim - European Series in Industrial Management, Volume 6)

LUNDVALL, B. A.; JOHNSON, B.:

The learning economy.

In: Journal of Industry Studies,

Kensington, 1(1994)2, pp. 23-42.

NONAKA, I.; TAKEUCHI, H.:

The Knowledge Creating Company.

New York, NY: Oxford University Press, 1995.

PRITSHOW, G.; WELDE, K.:

Übersicht über Prozessschnittstellen - Zukunftsperspektiven.

IuK - Schnittstellen in der Produktionstechnik.

Düsseldorf: VDI-Verlag, 2002.

(Fortschritt-Berichte VDI, Nr. 593)

PROBST, G.; RAUB, S.; ROMHARDT, K. (edts.):

Wissen managen. Wie Unternehmen ihre wertvollste Ressource optimal nutzen.

Frankfurt/Main: FAZ, 3rd ed., 1999.

REINER, J.:

Object Oriented Modelling for Manufacturing Automation.

Wroclaw, University of Technology, PhD Thesis, 2003.

RÜMLER, Reinhard:

Wissensbarrieren behindern effektives Wissensmanagement.

In: Wissensmanagement,

Mindelheim, (2001)5, pp. 24-27.

TAKEUCHI, H.:

Beyond Knowledge Management: Lessons from Japan.

Edt.: TAKEUCHI, $\mathrm{H}$.

June 1998.

http://www.sveiby.com/articles/LessonsJapan.htm, 25.07.2003. 